Research Paper

\title{
Bone Morphogenetic Protein-9 Induces Osteogenic Differentiation of Rat Dental Follicle Stem Cells in P38 and ERKI/2 MAPK Dependent Manner
}

\author{
Conghua $\mathrm{Li}^{1}$, Xia Yang${ }^{\circledR}$, Yujuan $\mathrm{He}^{2}$, Guo Ye ${ }^{1}$, Xiaodong $\mathrm{Li}^{1}$, Xiaonan Zhang1, Lan Zhou², Feng Deng ${ }^{\circledR}$ \\ 1. Department of Stomatology, Research Center for Oral Diseases and Biomedicine in Chongqing, Affiliated Stomatological Hospital, \\ Chongqing Medical University, Chongqing 400015, China; \\ 2. Key Laboratory of Clinical Laboratory Science of the Ministry of Education, Chongqing Medical University, China.
}

\begin{abstract}
$\square$ Corresponding author: deng63@263.net, graceyx@163.com.
() Ivyspring International Publisher. This is an open-access article distributed under the terms of the Creative Commons License (http://creativecommons.org/ licenses/by-nc-nd/3.0/). Reproduction is permitted for personal, noncommercial use, provided that the article is in whole, unmodified, and properly cited.
\end{abstract}

Received: 2012.08.12; Accepted: 2012.09.17; Published: 2012.11.05

\begin{abstract}
Dental follicle stem cells are a group of cells possessing osteogenic, adipogenetic and neurogenic differentiations, but the specific mechanism underlying the multilineage differentiation remains still unclear. Great attention has been paid to bone morphogenetic protein-9 (BMP-9) due to its potent osteogenic activity. In the present study, rat dental follicle stem cells were isolated and purified, and cells of passage 3 underwent adenovirus mediated BMP-9 gene transfection to prepare dental follicle stem cells with stable BMP-9 expression. Detection of alkaline phosphatase (ALP) and calcium deposition showed dental follicle stem cells transfected with BMP-9 gene could significantly promote the osteogenesis. In addition, SB203580 and PD98059 were employed to block the P38 mitogen-activated protein kinase (P38MAPK) and extracellular signal-regulated kinase (ERKI/2), respectively. Detection of ALP and calcium deposition revealed the BMP-9 induced osteogenic differentiation of dental follicle stem cells depended on MAPK signaling pathway.
\end{abstract}

Key words: Dental follicle stem cells; rat recombinant adenovirus transfection; bone morphogenetic protein-9; osteogenic differentiation; signaling pathway.

\section{Introduction}

Periodontitis is a chronic infectious disease affecting the tissues that surround and support the teeth and usually caused by the microorganism infection in the dental plaques. Periodontitis may cause the inflammation of the periodontal supporting tissues, formation of periodontal pocket, progressive attachment loss and alveolar bone absorption, which finally result in loose and loss of teeth. Periodontitis is one of immemorial and common diseases and a major cause of tooth loss in adults. The final goal of periodontitis treatment is to repair the periodontal defect and reconstruct normal structure and function of periodontal tissues. However, no effective strategy has been developed to promote the regeneration of periodontal tissues in the supragingival pocket and actual biological repair is lacking [1]. Tooth related stem cells and tissue engineering technique makes biological repair of periodontal tissues and teeth possible. That is, biological engineering technique has been employed for regeneration of periodontal tissues $[2,3]$. This is also a method to manually mimic the development of periodontal tissues. It is following the principles in the development of periodontal tissues that tissue regeneration be realized.

Dental follicle is composed of heterogeneous cells. Dental follicle cells serve as precursor cells of 
periodontal tissues and have characteristics of stem cells: self-renewal and multilineage differentiation potential suggesting the presence of stem cells in the dental follicle cells. Luan et al [4] prepared immortalized dental follicle cells from mice, suggesting that the dental follicle cells carrying heterogeneous cells have some stem cells. Morsczeck et al [5] found that in vitro human dental follicle cells could express Notch-1 and Nestin, and in vitro induction led to formation of membrane-like structure and calcified nodules. In mice with severe immunodeficiency, these cells could induce the formation of fibrous tissues with toughness in nature. These findings demonstrate that dental follicle cells have the characteristics of certain stem cells. In 2007, Kémoun et al [6] for the first time reported that human dental follicle cells could express Stro-1, a marker for mesenchymal stem cells (MSC). In 2008, Yao et al [7] for the first time confirmed the existence of dental follicle stem cells (DFCs), and the rat dental follicle cells could be induced to differentiate into adipocytes and neurons in vitro, which further confirm that the dental follicle cells have the mesenchyma derived cells which possess the potent differentiation potential. Thus, to isolate DFCs may be critical for the investigation of development of periodontal tissues. In addition, investigations on DFCs may provide evidence for the dental implant, tooth replantation and tooth regeneration. These cells with potent proliferation and differentiation may serve as favorable seed cells for the tissue engineering of periodontal tissues.

Bone morphogenetic proteins (BMPs) are a group of glycoproteins playing important roles in the development and remodeling of the bone, and they can promote the chemotaxis and aggregation of cells into osteogenic site in different ways and facilitate the differentiation into osteoblasts. In addition, these proteins can also promote the angiogenesis, regulate the activity of some growth factors and affect the production of these growth factors, which is helpful for the osteogenesis. BMPs have been considered as the most potent growth factors that can promote the bone regeneration. To date, more than $20 \mathrm{BMPs}$ have been identified and BMP-2, $-4,-6$ and -7 have found to the osteogenic potential [8-12]. BMP-9 is also known as growth differentiation factor 2 (GDF-2) and mainly expressed in the liver [13]. BMP-9 can induce and maintain the cholinergic differentiation of embryonic neurons, regulate the metabolism of glucose and fatty acid, modulate the dynamic balance of iron and exert other important biological functions [14-16]. However, the role of BMP-9 in the osteogenesis and bone regeneration is poorly understood. TC HE systemically investigated the roles of 14 BMPs (BMP-2-15) in the oseogenesis. The results demonstrated the potent osteogenic activity of BMP-9 [17-18]. To date, no study has been conducted to investigate the effect of BMP-9 on dental follicle cells and its role in the dental bone regeneration. In the present study, adenovirus served as a vector mediating the transfection of BMP-9 into DFCs. RT-PCR was employed to detect the transfection efficiency, and the early and late osteogenesis of these DFCs were identified. Moreover, the role of p38 and ERK1/2 MAPK signaling pathway in the BMP-9 induced osteogenesis of rat DFC. Our results provide evidence that DFCs may become promising seed cells for periodontal bone regeneration in tissue engineering.

\section{Materials and methods}

\section{Reagent}

Dulbecco's Modified Eagle Medium (DMEM), fetal bovine serum (FBS), $0.25 \%$ trypsin (GIBCO, USA), alkaline phosphatase (ALP) detection kit (BD, USA), Naphthol AS-MX Phosphate Alkaline Solution, Fast Blue RR salt (Sigma, USA), Oil Red O (WOLSEN), bovine serum albumin (BSA), vitamin C, $\beta$-glycerophosphate, $2 \%$ alizarin red S (pH: 4.2) (Sigma, USA), $0.25 \%$ Triton X-100(mouse monoclonal IgG; Santa cruz, USA), rabbit anti-rat vimentin monoclonal antibody, rabbit anti-rat CK monoclonal antibody (Sigma, USA), rat SP detection kit, ultrasensitive goat two-step detection kit for immunohistochemistry, DAB kit (Beijing Zhongshan Golden Bridge Biotech), monoclonal antibodies against CD31, CD146 and STRO-1 (Invitrogen, USA), RIPA (Shanghai Biyoutime Biotech) protease inhibitor, phosphatase inhibitor (Roche, Switzerland), SB203580 (P38MAPK specific inhibitor; dissolved in DMSO at $20 \mathrm{mmol} / \mathrm{L}$ and stored at $-20^{\circ} \mathrm{C}$ ) and PD98059 (ERK1/2 specific inhibitor; dissolved in DMSO at $50 \mathrm{mmol} / \mathrm{L}$ and stored at $-20^{\circ} \mathrm{C}$ ) (Santa cruz, USA) were used in the present study[19].

\section{Experimental animals}

A total of 40 specific pathogen free SD neonatal rats aged 6 7 days and weighing 20-30 g (male: female $=1: 1$ ) were purchased from the Experimental Animal Center of Chongqing Medical University (License No: SYXK[Yu]20040001). The procedures in the present study were in accordance with the National Institute of Health guidelines on the ethical use of animals[20].

\section{Isolation and culture of rat DFCs}

Mouse DFCs were obtained from first lower molars of D6 mice and cultured as described previ- 
ously [21]. Briefly, the neonatal rats were sacrificed by decapitation, and the first and second molar germs were obtained. The dental follicle tissues were added to the serum-free DMEM and then cut into $1-\mathrm{mm}^{3}$ blocks. Centrifugation was done at $800 \mathrm{rpm} / \mathrm{min}$ for 5 min and the supernatant was removed. Then, $0.1 \%$ type I collagenase $(3 \mathrm{ml})$ was added followed by digestion at $37^{\circ} \mathrm{C}$ for $1 \mathrm{~h}$. Following addition of $1 \mathrm{ml}$ of $0.25 \%$ trypsin, digestion continued at $37^{\circ} \mathrm{C}$ for $5 \mathrm{~min}$. Then, DMEM containing 15\% FBS was added to stop the digestion followed by centrifugation at 800 $\mathrm{rpm} / \mathrm{min}$ for $5 \mathrm{~min}$. The supernatant was removed and cells were re-suspended in $3 \mathrm{ml}$ of DMEM containing 15\% FBS, $100 \mathrm{U} / \mathrm{ml}$ penicillin and $100 \mu \mathrm{g} / \mathrm{ml}$ streptomycin and incubated in a humidified environment with $5 \% \mathrm{CO}_{2}$ at $37^{\circ} \mathrm{C}$. The medium was refreshed every 3 days. When the primary dental follicle cells became monolayer-like and cell confluence reached about $80 \%$, passaging was performed. Cells in the logarithmic growth phase were used for preparation of single cell suspension and dental follicle cells were labeled with STRO-1 antibody, a marker of MSC. Following washing in buffer twice, mouse IgM immune breads at $2-8^{\circ} \mathrm{C}$ were added followed by incubation for $15 \mathrm{~min}$. After washing in buffer twice, cells were re-suspended and these cells were added to the cylinder. The STRO-1 positive cells were seperated by using the immunomagnetic bead sorter and maintained in DMEM containing 15\% FBS, $100 \mathrm{U} / \mathrm{ml}$ penicillin and $100 \mu \mathrm{g} / \mathrm{ml}$ streptomycin in a humidified environment with $5 \% \mathrm{CO}_{2}$ at $37^{\circ} \mathrm{C}$.

\section{Adenovirus mediated transfection of DFCs}

The recombinant adenovirus carrying BMP-9 (Ad-BMP9) and Ad-GFP were kindly provided by the Prof He in the Medical Center of University of Chicago, USA. The medium for osteogenesis included 50 $\mu \mathrm{g} / \mathrm{ml}$ vitamin C $(0.5 \mathrm{~g}$ of vitamin $C$ in $10 \mathrm{ml}$ of deionized water followed by filtration and storage at $4^{\circ} \mathrm{C}$ ) and $100 \mathrm{mM}$ glycerophosphate (2.16 g of glycerophosphate in $100 \mathrm{ml}$ of deionized water). The rat DFCs with good growth were used to prepare single cell suspension one day before transfection and then seeded into 24-well at a density of $5 \times 10^{3} / \mathrm{ml} /$ well. When the cell confluence reached $80 \% 24 \mathrm{~h}$ later, the DMEM in each well was removed. Then, $5 \mu \mathrm{l}$ of Ad-rRBMP-9 with multiplicity of infection (MOI) of 100 was mixed with $0.8 \mathrm{ml}$ of medium, and this solution was added to each well. Gentle shaking was performed to make the solution cover the cells in each well. In the negative control group, $30 \mu \mathrm{l}$ of Ad-GFP was added. Following addition of BMP-9, cells were incubated at $37^{\circ} \mathrm{C}$ in a humidified environment with $5 \% \mathrm{CO}_{2}$. Four hours later, $2 \mathrm{ml}$ of medium was added followed by incubation. At $24 \mathrm{~h}$ after incubation, the medium was refreshed and the cell growth and morphology were observed under an inverted phase contrast microscope.

\section{RT-PCR}

Following transfection, the fluorescence in cells was observed under an inverted phase contrast microscope. At 3, 6, 9 and 12 days after transfection, cells in the transfection group and non-transfection group were collected and total RNA was extracted with Trizol by lysis and used to reverse transcribe into cDNA followed by amplification of BMP-9 by PCR. The reaction mixture $(25 \mu \mathrm{L})$ included $8.5 \mu \mathrm{L}$ of water, $12.5 \mu \mathrm{L}$ of SYBR, $1 \mu \mathrm{L}$ of forward primer, $1 \mu \mathrm{L}$ of reverse primer and $2 \mu \mathrm{L}$ of cDNA. The reaction condition included pre-denaturation at $95^{\circ} \mathrm{C}$ for $30 \mathrm{~s}$ and 35 cycles of denaturation at $95^{\circ} \mathrm{C}$ for $10 \mathrm{~s}$ and annealing at $64{ }^{\circ} \mathrm{C}$ for $30 \mathrm{~s}$. In the negative control group, cDNA was not added and GAPDH served as an internal reference [22]. Then, $3 \mu \mathrm{L}$ of products was separated by $1.5 \%$ agarose gel electrophoresis. The forward primer for BMP-9 was 5'- TGTACA ACA GGT ACA CGT CCG-3' and the reverse primer was $5^{\prime}$ - TGA ATG TCC TGG GAC ACC AG-3'. The anticipated size was $275 \mathrm{bp}$. Finally, the optical density of each band was determined.

\section{Histological staining}

Detection of ALP: 5-7 days after osteogenic induction in 24-well plate, the medium was removed and DFCs were washed in PBS twice. Then, $500 \mu l$ of fast blue BB was added followed by incubation in dark at room temperature for $30 \mathrm{~min}$. These cells were observed under light microscope.

Detection of calcium deposition: The cells in each group were washed in PBS thrice and $200 \mu \mathrm{l}$ of $0.5 \%$ glutaraldehyde was added to each well followed by fixation for $15 \mathrm{~min}$. The medium was removed and cells were washed in PBS thrice. Following addition of $200 \mu \mathrm{l}$ of $0.1 \%$ Alizarin Red -Tris- $\mathrm{HCl}$ (pH: 8.3), incubation was done at room temperature for $20 \mathrm{~min}$. After washing in PBS thrice, cells were observed under a microscope. When the red substance was present (about $5 \mathrm{~min}$ later), the staining solution was removed, and $\mathrm{ddH}_{2} \mathrm{O}$ was added to stop staining and rinse these cells. The DFCs without transfection served as a control group.

\section{Immunohistochemistry}

DFCs in the logarithmic growth phase were used to prepare single cell suspension after digestion, and then added to 6-well plate at a density of $1 \times 10^{4}$ cells/well. When the cell confluence reached about 
$80 \%$, cells were fixed in $4 \%$ paraformaldehyde. Then, these cells were washed with PBS for $5 \mathrm{~min}$ and treated with $2.5 \mathrm{ml} / \mathrm{L}$ Triton- 100 for $10 \mathrm{~min}$. After incubation with $30 \% \mathrm{H}_{2} \mathrm{O}_{2}$ for 30 min to block endogenous peroxidase, cells were treated with normal goat serum for $30 \mathrm{~min}$ at $37^{\circ} \mathrm{C}$. Then, these cells were incubated with rabbit anti-rat vimentin, keratin.Addition of goat anti-rabbit secondary antibody and visualization with $\mathrm{DAB}$ were done according to the manufacturer's instructions. Counterstaining with hematoxylin, dehydration in water, transparentization in xylene and mounting with neutral gum were done sequentially. In the negative control, the primary antibody was replaced with PBS. Cells with brown granules in the cytoplasm were regarded to be positive for target protein.

\section{Flow cytometry}

When the DFC confluence reached about 100\%, these cells were digested in $0.25 \%$ trypsin and the cell density was adjusted into $1 \times 10^{6} / \mathrm{ml}$. Then, $100 \mu \mathrm{l}$ of cell suspension was added to a tube followed by addition of FITC conjugated CD31, CD146 or STRO-1

fluorescence antibody (20 $\mu \mathrm{l}$ for each). Incubation was done in dark at room temperature for $30 \mathrm{~min}$. The cells were re-suspended in $1.4 \mathrm{ml}$ of washing buffer followed by centrifugation at $1300 \mathrm{rpm}$ for 5 min. After washing as abovementioned, the cells were re-suspended in 300-500 $\mu \mathrm{l}$ of washing buffer and subjected to flow cytometry for the detection of surface antigens.

\section{Detection of ALP activity}

The cells in the transfection group and non-transfection group were harvested. The supernatant was collected at $3,5,7$, and 10 days after culture (5 samples in each group). Detection of ALP activity was done according to the manufacturer's instructions. Absorbance (A) was detected at $520 \mathrm{~nm}$ and the A represents the ALP activity. The ALP activity was adjusted with the protein concentration.

\section{Western blot assay}

DFCs were maintained in dishes for $36 \mathrm{~h}$ and the medium was removed. These cells were washed in pre-cold PBS twice. Following addition of RIPA lysis buffer containing protease inhibitor, phosphatase inhibitor and $1 \mathrm{mM}$ PMSF (200 $\mu \mathrm{l} / 100 \mathrm{~mm}$ dish), incubation was done on ice for $30 \mathrm{~min}$, and the cells and lysate were collected into $1.5-\mathrm{ml}$ tube followed by centrifugation at $4^{\circ} \mathrm{C}$ for $15 \mathrm{~min}$ at $12000 \mathrm{rmp}$. The supernatant was transferred into new EP tubes followed by addition of loading buffer, which was boiled for 5-8 $\mathrm{min}$. The total protein was extracted from cells in each group and stored at $-20^{\circ} \mathrm{C}$. After preparation of stack gel and separating gel and loading of samples, SDS-PAGE was performed followed by transferring proteins for further assay.

\section{Statistical analysis}

Experiment was repeated at least 3 times with favorable repeatability. Data were expressed as mean \pm standard deviation (mean $\pm \mathrm{SD}$ ). Comparisons between two groups were done with $t$ test. Statistical analysis was performed with SPSS version 16.0 for windows. A value of $\mathrm{P}<0.05$ was considered statistically significant.

\section{Results \\ Isolation of DFCs}

Cell morphology: The STRO-1 positive cells were separated with immune bread sorter following digestion. Under an invert phase contrast microscope, the DFCs were adherent to the plate in a single-cell manner at $10 \mathrm{~h}$ after culture, and began to stretch at $24 \mathrm{~h}$ after culture. At $72 \mathrm{~h}$ after culture, the majority of cells stretched. At 15-18 days after culture, the cell confluence reached about $80-90 \%$, and these cells generated colonies with the colony formation rate of $1-23 / 10^{5}$. These cells were spindle-like or polygonal. The cytoplasm was transparent, cell body was full and about 1-3 nucleoli could be identified in each cell. In the polygonal cells, the cell skeleton was clear. The DFCs had characteristic structures such as homogeneous electron-dense granules and a lot of lysosomes suggesting the active differentiation and remodeling of tissues or organs; the cytoplasm was rich in mitochondria, Golgi apparatus and rough endoplasmic reticulum in the cytoplasm. Moreover, the extracellular matrix increased over time (Fig.1A). The cells were closely arranged in a swirling manner. About 7-10 days later, the cell confluence could reach $80-90 \%$. Then, these cells were harvested after passaging for identification (Fig. 1B).

Immunohistochemistry and phenotype determination: Immunohistochemistry was performed for Vim and CK. Results showed the DFCs were positive for Vim and had brown granules in the cytoplasm. The nucleus was stained dark blue. These cells were negative for $\mathrm{CK}$, but the cytoplasm was not stained except for the nuclei being staining blue. These findings demonstrated that DFCs were derived from the ectodermal mesenchyma (Fig.1C). Flow cytometry revealed that the Stro- 1 positive rate of DFCs was $6.7 \%$, CD146 positive rate was $51.5 \%$ and CD31 positive rate was $7.5 \%$ (Fig.1D). 
A

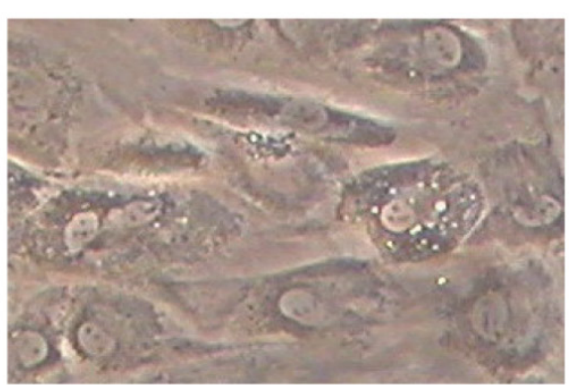

B

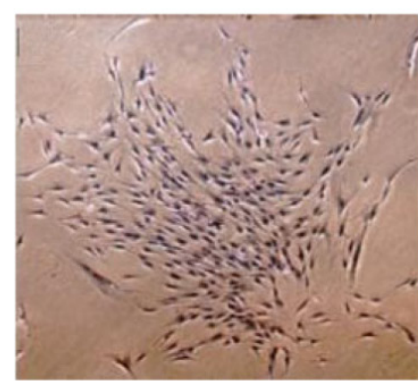

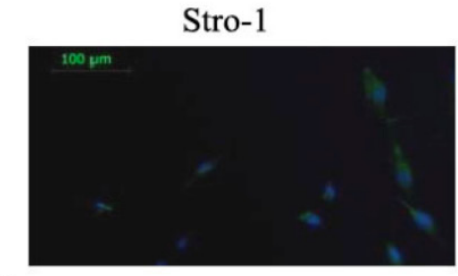

C

$\mathrm{D}$

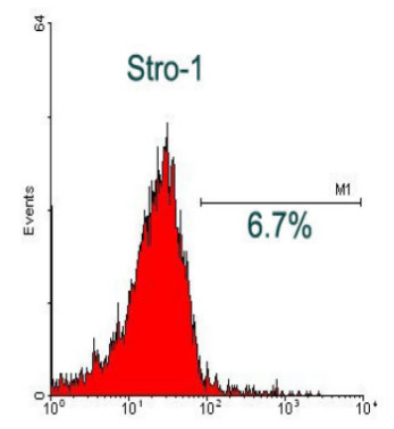

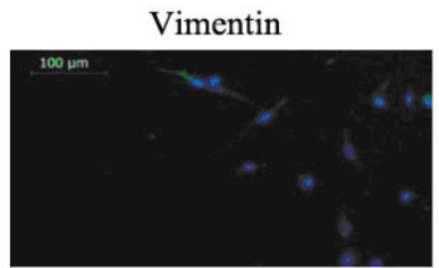

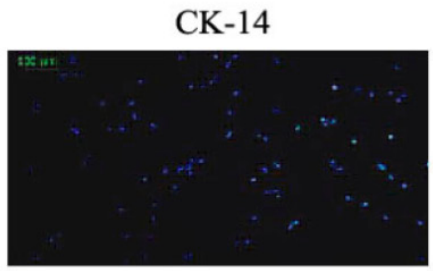

CK-14
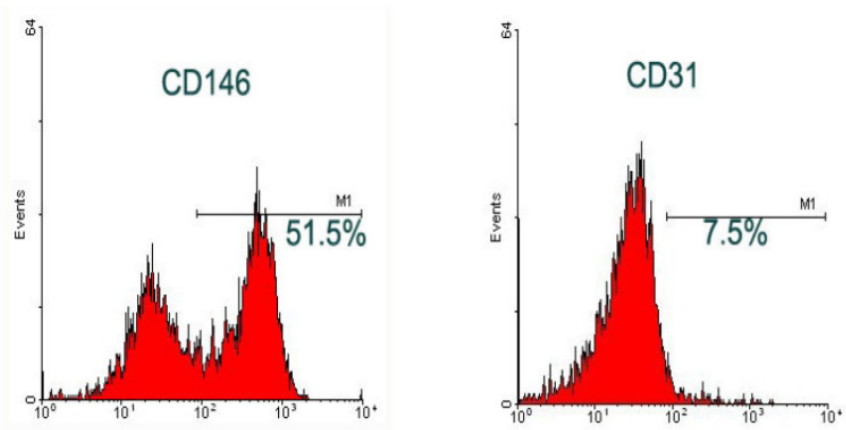

Figure I. Separation and identification of DFCs. A: DFCs had characteristic structures including homogeneous electron-dense granules and a lot of lysosomes suggesting the active differentiation and remodeling of tissues or organs; B: DFCs formed colonies and had potent proliferative activity; C: immunohistochemistry and phenotyping to determine the source of cells. DFCs were labeled with Stro-I and were found to be positive for Vimentin but negative for CK-I4; D: Flow cytometry was done to measure the surface antigens.

Multilineage differentiation potential of DFCs: Under different inductions, DFCs could differentiate into different types of cells. These cells had the characteristics of stem cells having the osteogenic, adipogenic and neurogenic potentials. Under the osteogenic induction, these cells did not present with adipogenic and neurogenic potentials (data not shown).

\section{DFCs with stable BMP-9 expression following transfection}

After adenovirus mediated transfection of BMP-9, RT-PCR showed a band at $275 \mathrm{bp}$, and the optical density of this band increase over time. In the untransfection group, this band was not found, which suggested no mRNA expression of BMP-9 (Fig. 2A). At $12 \mathrm{~h}$ after Ad-rRBMP-9 mediated transfection, fluorescence was found in the DFCs, especially at the perinuclear area, and reached a maximal level at $48 \mathrm{~h}$ (Fig. 2B). After transfection, the quiescent phase was prolonged, the cell number slightly reduced, and the doubling time was about $72 \mathrm{~h}$. The growth curve of DFCs was S-shaped. In the first 3 days after transfection, these cells were in the quiescent phase and then entered the logarithmic phase. At 8 days after transfection, the cell growth was suppressed and the cell number remained stable (Fig. 2C).

\section{BMP-9 transfection significantly increases os- teogenesis of DFCs}

Under a light microscope, the cell morphology remained unchanged in the transfection group and non-transfection group (data not shown). Detection of ALP activity: In the osteogenic induction group, BMP-9 group and osteogenic induction + BMP-9 
group, the ALP activity was markedly increased at 3, 5 and 7 days after Ad-rRBMP-9 mediated transfection, when compared with GFP group and blank control group (Each experiment was repeated three times, with the average value as the experimental results, $\mathrm{P}=0.0079<0.01$ ), and the increase in ALP activity was the most evident on day 7 (Fig. 3A). Immunohistochemistry for ALP also showed the expression of ALP in the BMP-9 group was significantly increased when compared with the GFP group and blank control group (Fig.3B).

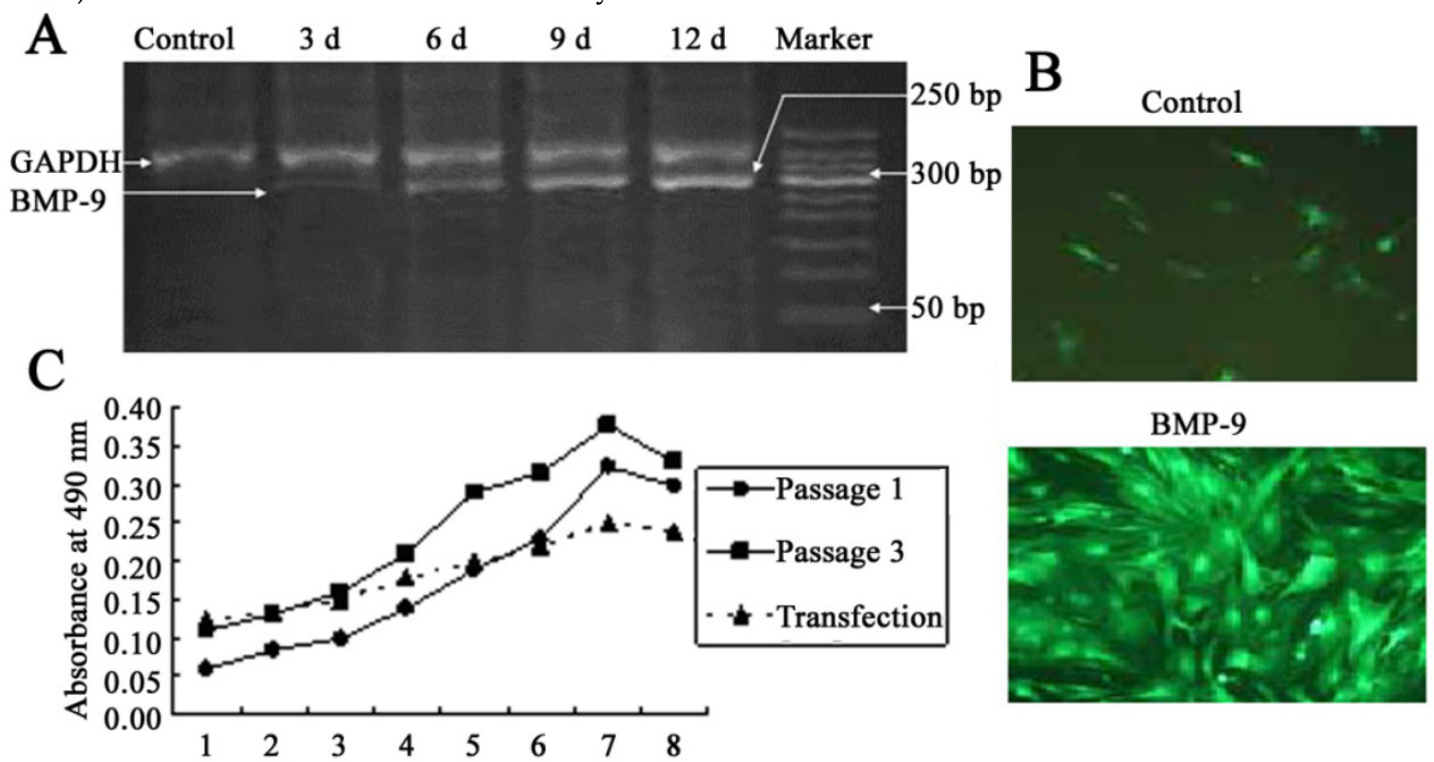

Figure 2. DFCs following BMP-9 transfection. A: Detection of BMP-9 mRNA expression by RT-PCR; B: Following transfection, the DFCs presented with fluorescence $(\times 100)$ and calcified nodules. In the control group, scattered non-specific fluorescence was present; $C$ : Comparisons of growth curve of DFCs between transfection group and untransfection group (DFCs of Ist and $3^{\text {rd }}$ generation).

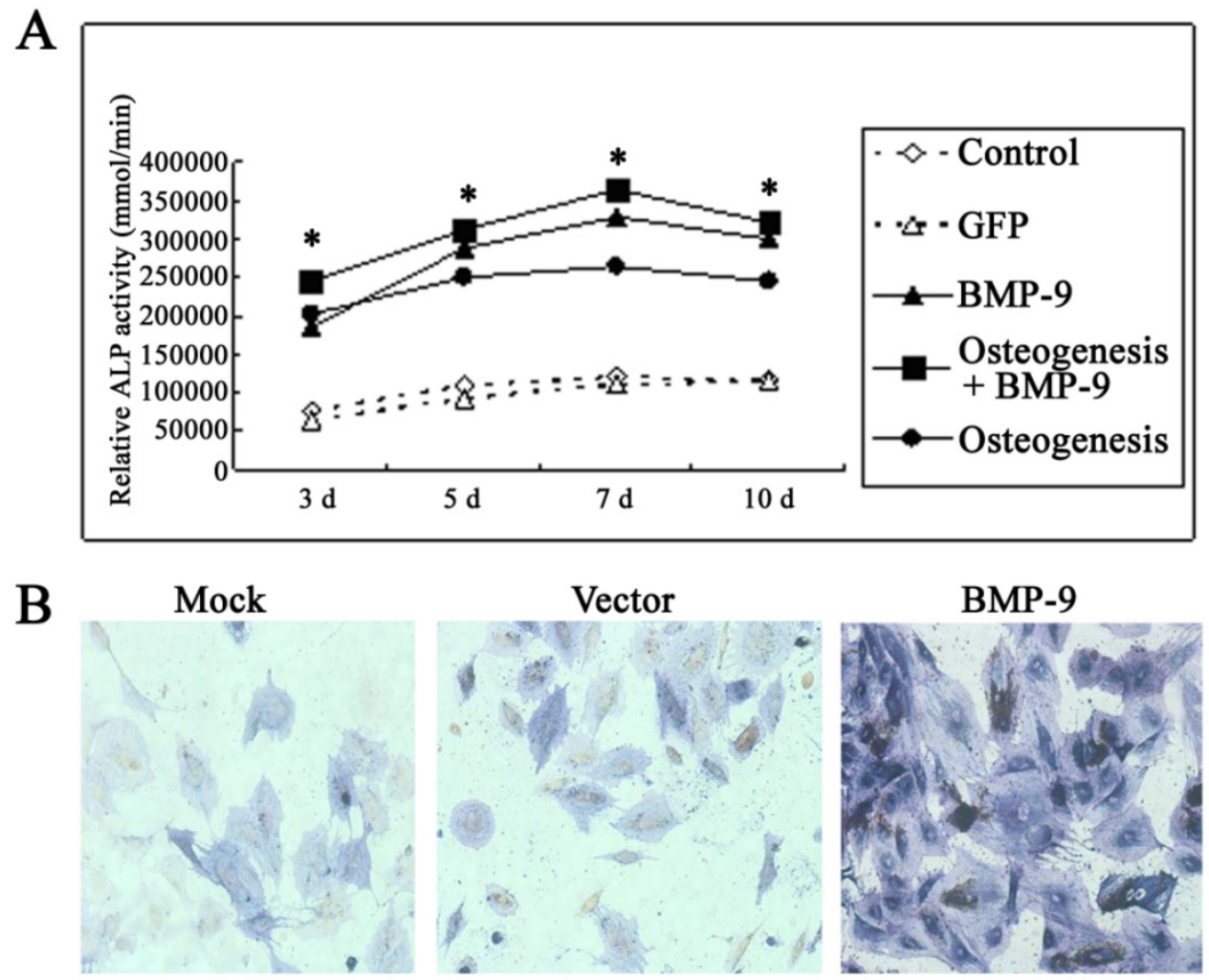

Figure 3. BMP-9 promoted the osteogenesis of DFCs. A: Detection of ALP activity. B: immunohistochemistry for ALP: the ALP expression was markedly increased in the BMP-9 group when compared with the mock group and vector group. 
At $14 \mathrm{~d}$ after Ad-rRBMP-9 mediated transfection, Alizarin Red staining showed some calcified nodules which were large and red, suggesting the increased osteogenesis of DFCs following transfection (Fig. 5). In the non-transfection group, the calcified nodules were occasionally found and lightly stained (Fig. 5).

\section{Regulation of osteogenic differentiation of BMP-9 transfected DFCs by MAPK signaling pathway}

Activation of MAPK signaling pathway by BMP-9: Cells were seeded into $100-\mathrm{mm}$ dishes and transfection was done with Ad-BMP9 or Ad-GFP at an appropriate MOI (transfection efficiency of $50-60 \%$ ). At $12 \mathrm{~h}$ after transfection, cells were maintained in serum free DMEM/High Glu for $36 \mathrm{~h}$. Then, total protein was extracted and western blot assay was done to detect target proteins. Results showed BMP-9 transfection did not change the expression of total p38 and total ERK1/2, but the expression of phosphorylated p38 was markedly increased and ERK1/2 decreased (Fig. 4A).
$\mathbf{A}$

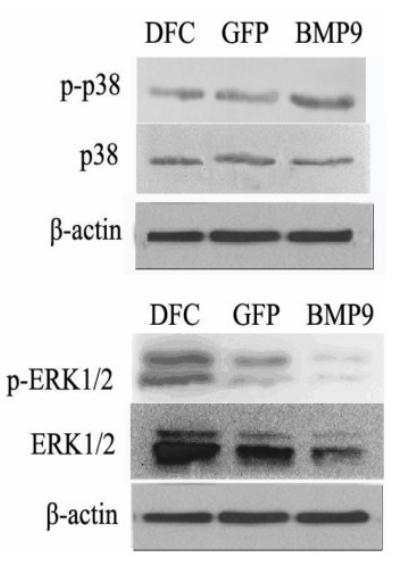

C

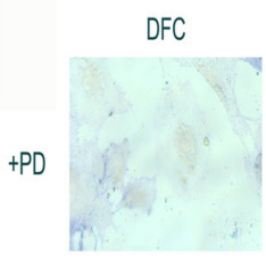

DFC

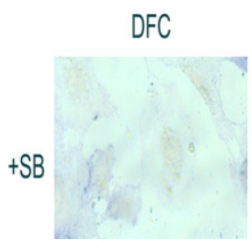

GFP+DMSO

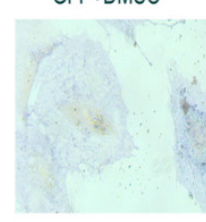

GFP+DMSO
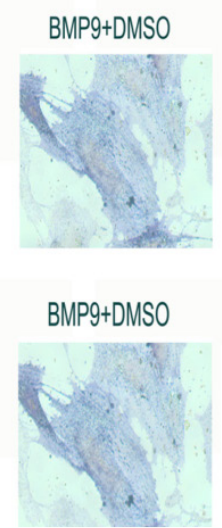

BMP9+DMSO
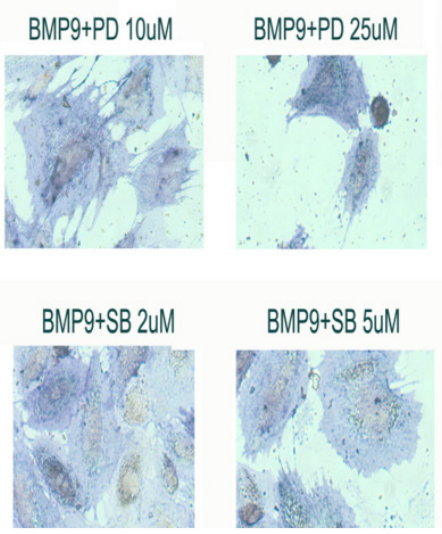

B

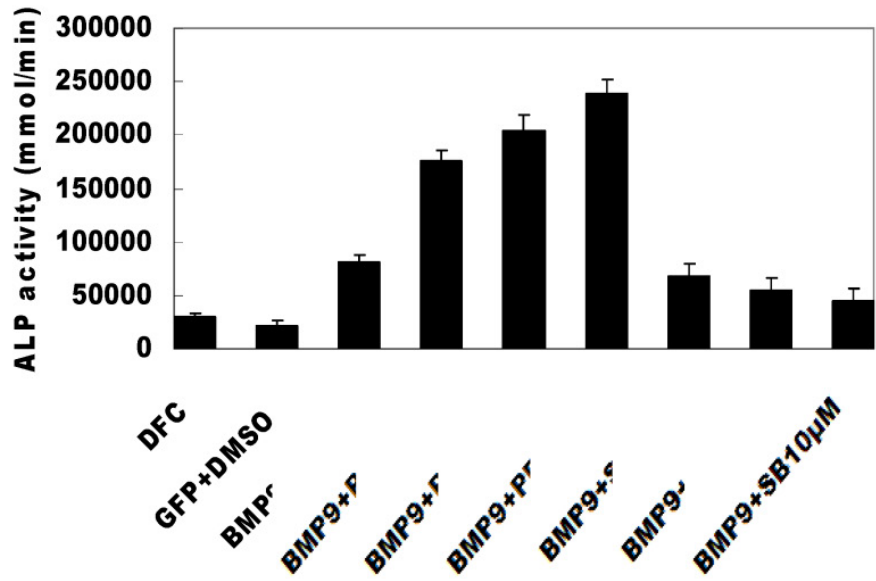

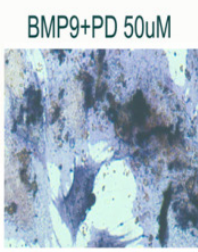

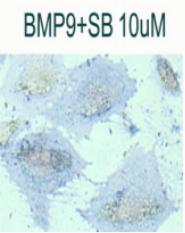

Figure 4. MAPK signaling pathway regulated osteogenic differentiation of BMP-9 transfected DFCs. A: Western blot assay showed BMP-9 activated MAPK signaling pathway and increased the phosphorylation of $\mathrm{p} 38$ and ERKI/2. P38MAPK inhibitor suppressed the early osteogenic differentiation of BMP-9 transfected DFCs in a concentration dependent manner; ERKI/2 inhibitor promoted the early osteogenic differentiation of BMP-9 transfected DFCs in a concentration dependent manner: B: ALP activity; C: ALP staining (I50x); Findings demonstrated that the evident osteogenic effect of DFCs after transfection. 

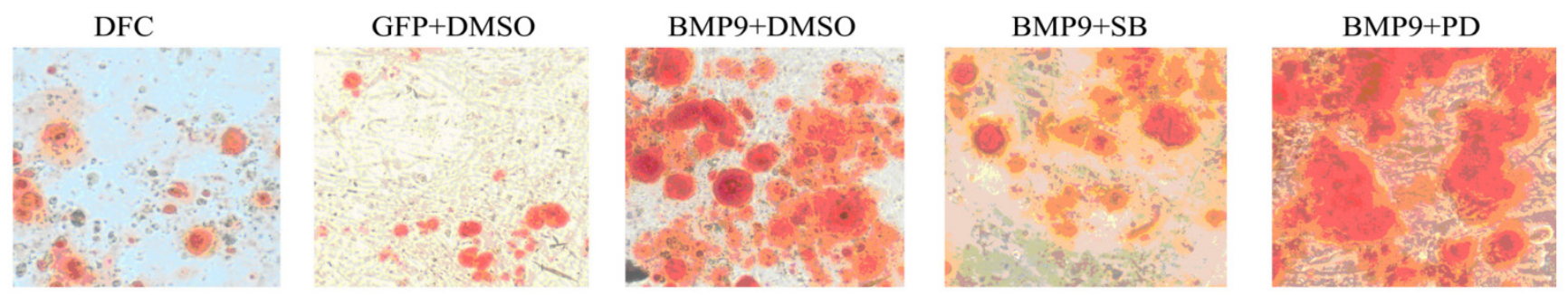

Figure 5. Alizarin Red staining was done to detect calcium deposition (I50x). When compared with the GFP/DMSO group, the number of calcified nodules was markedly increased in the BMP9/DMSO group. Compared with the BMP9/DMSO group, the number of calcified nodules in the BMP9/SB group significantly reduced and the number of calcified nodules in the BMP9/PD was significantly higher.

\section{Effect of MAPK signaling pathway inhibition on early osteogenic differentiation of BMP-9 transfected DFCs}

The BMP-9 transfected DFCs were independently treated with $2 \mu \mathrm{mol} / \mathrm{L}, 5 \mu \mathrm{mol} / \mathrm{L}$ and 10 $\mu \mathrm{mol} / \mathrm{L}$ SB203580, an inhibitor of p38MAPK. Seven days later, detection of ALP activity and ALP staining were performed to study the osteogenesis. Results showed treatment with SB203580 at different concentrations reduced the ALP activity of BMP-9 transfected cells suggested a concentration dependent manner. The inhibition was the most evident after treatment with $25 \mu \mathrm{mol} / \mathrm{L}$ SB203580. Significant difference in ALP activity was noted between BMP9/DMSO group and other groups $(\mathrm{P}<0.05)$ (Fig. 4B). ALP staining revealed the staining intensity of ALP reduced with the increase in SB203580 concentration, which was consistent with findings in detection of ALP activity (Fig. 4C).

The BMP-9 transfected DFCs were independently treated with $10 \mu \mathrm{mol} / \mathrm{L}, 25 \mu \mathrm{mol} / \mathrm{L}$ and 50 $\mu \mathrm{mol} / \mathrm{L}$ PD98059, an inhibitor of ERK1/2. Seven days later, detection of ALP activity and ALP staining were performed to study the osteogenesis following adjustment by cell count. Results showed treatment with PD98059 at different concentrations increased the ALP activity of BMP-9 transfected cells. When the PD98059 was at low concentrations $(<50 \mu \mathrm{mol} / \mathrm{L})$, this effect was in a concentration dependent manner (Fig. 4B). Significant difference in ALP activity was noted between BMP9/DMSO group and other groups $(\mathrm{P}<0.05)$. ALP staining revealed the staining intensity of ALP increased with the increase in PD98059 concentration, which was consistent with findings in detection of ALP activity (Fig. 4C).

\section{Effect of MAPK signaling pathway inhibition on late osteogenic differentiation of BMP-9 transfected DFCs}

The BMP-9 transfected DFCs were treated with
$10 \mu \mathrm{mol} / \mathrm{L}$ SB203580 and $50 \mu \mathrm{mol} / \mathrm{L}$ PD98059. Twenty one days later, Alizarin Red staining was performed to detect the calcium deposition. Results showed, In the BMP9/SB group, the calcified nodules significantly reduced as compared to the BMP9/DMSO group. When compared with the GFP/DMSO group, the number of calcified nodules was markedly increased in the BMP9/DMSO group. In addition, the number of calcified nodules in the BMP9/PD was significantly higher than that in the BMP9/DMSO group (Fig.5).

\section{Discussion}

On the basis of principles in the development of periodontal tissues, tooth related stems and tissue engineering technique may realize the tissue regeneration. However, the selection of seed cells is a determinant. The ideal seed cells have the following requirements: ease collection, stable nature after transplantation and potent proliferation and differentiation $[28,29]$. The dental follicle is loose connective tissues between the enamel in the pre-eruptive phase and tissues surrounding the dental papilla and can develop into periodontal tissues. Dental follicle is derived from ectodermal mesenchyma. The cementoblasts in the inner layer of the root of the tooth can secret cementum, and the cells close to the alveolar bone can differentiate into osteoblasts which can secret bone matrix. The cells in the middle layer can differentiate into fibroblasts which may produce the periodontal membrane fiber. Numerous studies have confirmed that dental follicle is composed of heterogeneous cells. The dental follicle cells are considered as precursor cells of periodontal tissues and have the characteristics of stem cells: self-renewal and multilineage differentiation potential $[7,30]$. In the present study, the rat dental follicle cells were easy to separate and culture and had active proliferation. The doubling time was short, and cells remained stable after passaging. STRO-1 is a marker of stem cells from ectodermal mesenchyma. In this study, immune breads 
were used to sort STRO-1 positive DFCs which were found to have multilineage differentiation potential. Under the osteogenic induction, these cells presented with osteogenic differentiation, but not adipogenic or neurogenic differentiation.

BMP-9 is one of proteins in the BMP family and less investigated. BMP-9 is one of potent osteogenic growth factors and has been found to possess the capability to promote the osteogenesis and chondrogenesis $[32,33]$. The ability of BMP-9 to induce the osteogenic differentiation of stem cells was found to more potent than other BMPs such as BMP-2, and BMP-7 [34]. In the present study, adenovirus carrying GFP was used to mediate the BMP-9 transfection into DFCs. These cells were successfully transfected and favorable transfection efficiency was present. RT-PCR showed the BMP-9 transfected DFCs had stable expression of BMP-9. The growth curve of cells in the transfection group and untransfection group was also measured. Results showed Ad-rRBMP-9 had influence on the growth of DFCs. Following transfection, these cells were transiently in the quiescent phase and the doubling time was increased, but the proliferation of these cells was not compromised. Appropriate amount of cells could be obtained for therapy. The influence of Ad-rRBMP-9 on the DFCs may be attributed to the stimulation of DFCs by the adenovirus, but the specific mechanism is required to be further studied.

In the present study, osteogenic induction was performed in DFCs. Results showed, in the absence of virus, the cell state and growth were good. Addition of virus led to the death or arrest of these cells. 7 and 10 days after osteogenic induction, the ALP activity in DFCs was markedly higher than that in the positive control group and blank control group. ALP activity is a marker of early differentiation of osteoblasts. These findings demonstrated the osteogenic capability of DFCs which can differentiate into osteoblasts. These also confirmed the important role of BMP-9 in the osteogenesis of DFCs.

Previous studies [16, 35] revealed BMPs exert osteogenic effect which depends on the Smad dependent pathway. In recent studies, increasing evidence showed $[9,10]$ BMPs could exert effect in non-Smad dependent pathways (such as MAPKs and PI3K) in which the Smad activation is not required. These pathways are also known as non-canonical pathways, of which MAPK signaling pathway is an important one. BMP-2, BMP-4 and BMP-7 can exert effect in a MAPK dependent manner, and the MAPK signal transduction is also crucial for the BMPs induced osteogenesis. Similar to other BMPs, BMP-9 can serve as a potent osteogenic factor to active the ca- nonical Smad signaling pathway [35-38]. Whether BMP-9 can activate non-canonical MAPK signaling pathway is still unclear.

Our results showed, following BMP-9 transfection, the phosphorylated MAPKp38 and ERK1/2 increased, suggesting that BMP-9 can directly or indirectly activate MAPK signaling pathway. BMP-9 activates P38MAPK signaling pathway to promote the osteogenic differentiation of dental follicle cells. However, BMP-9 inhibits the ERK1/2, which then suppresses the osteogenic differentiation of dental follicle cells. After administration of P38MAPK inhibitor (SB203580) and/or ERK1/2 specific inhibitor (PD98059) to suppress the MAPK signaling pathway, the ALP activity, calcium deposition were determined. Results showed 1) Inhibition of p38MAPK expression reduced the ALP activity and calcium deposition in BMP-9 transfected cells; 2) inhibition of ERK1/2 activity increased the ALP activity and calcium deposition in BMP-9 transfected cells.

Taken together, our results reveal BMP-9 can be used as a factor to induce the osteogenesis of DFCs in a time dependent manner in which MAPK signaling pathway involves. Dental follicle cells can serve as seed cells in the tissue engineering of periodontal tissues. Our findings provide evidence for future studies on local application of BMP-9 aiming to control the healing of periodontal bone defect and regeneration of periodontal tissues.

\section{Acknowledgement}

We thank Pro He TC in Medical Center of University of Chicago, USA, Prof Luo JY, Zhou L and He YJ in the Department of Clinical Laboratory Center of Chongqing Medical University. This study was supported by the Medical Scientific Research Program of Health Bureau of Chongqing (2012-1-056), Chongqing Science \& Technology Commission of Yuzhong district (20110312) and the National Natural Science Funds of China (81271183).

\section{Competing Interests}

The authors have declared that no competing interest exists.

\section{References}

1. Akizuki T, Oda S, Komaki M, Tsuchioka H, Kawakatsu N, Kikuchi A, Yamato M, Okano T, Ishikawa I. Application of periodontal ligament cell sheet for periodontal regeneration: a pilot study in beagle dogs. J Periodontal Res, 2005; 40(3):245-251.

2. Polimeni G, XiroPaidis AV, Wikesjö UM. Biology and principles of periodontal wound healing/regeneration. J Periodontol 2000. 2006; 41:30-47.

3. Yokoi T, Saito M, Kiyono T, Iseki S, Kosaka K, Nishida E, Tsubakimoto T, Harada H, Eto K, Noguchi T, Teranaka T. Establishment of immortalized dental follicle cells for generating periodontal ligament in vivo. Cell Tissue Res. 2007;327(2):301-11. 
4. Luan X, Ito Y, Dangaria S, Diekwisch TG. Dental follicle progenitor cell heterogeneity in the developing mouse periodontium. Stem Cells Dev. 2006;15(4):595-608

5. Morsczeck C, Götz W, Schierholz J, Zeilhofer F, Kühn U, Möhl C, Sippel $\mathrm{C}$, Hoffmann $\mathrm{KH}$. Isolation of precursor cells (PCs) from human dental follicle of wisedom teeth. Matrix Biol. 2005; 24(2):155-165.

6. Kémoun P, Laurencin-Dalicieux S, Rue J, Farges JC, Gennero I, Conte-Auriol F, Briand-Mesange F, Gadelorge M, Arzate H, Narayanan AS, Brunel G, Salles JP. Human dental follicle cells acquire cementoblast features under stimulation by BMP-2/-7 and enamel matrix derivatives (EMD) in vitro. Cell Tissue Res. 2007; 329(2):283-294

7. Yao S, Pan F, Prpic V, Wise GE. Differentiation of Stem Cells in the Dental Follicle. J Dent Res. 2008; 87(8):767-771.

8. McIntosh CJ, Lawrence S, Smith P, Juengel JL, McNatty KP. Active immunization against the proregions of GDF9 or BMP15 alters ovulation rate and litter size in mice. Reproduction. 2012; 143(2):195-201

9. Valentin-Opran A, Wozney J, Csimma C, Lilly L, Riedel GE. Clinical evaluation of recombinant human bone morphogenetic protein-2. Clin Orthop Relat Res. 2002; 395:110-20

10. Kaneda A, Fujita T, Anai M, Yamamoto S, Nagae G, Morikawa M, Tsuji S, Oshima M, Miyazono K, Aburatani H. Activation of Bmp2-Smad1 Signal and Its Regulation by Coordinated Alteration of H3K27 Trimethylation in Ras-Induced Senescence. PLoS Genet. 2011; 7(11):e1002359

11. Açil Y, Springer IN, Broek V, Terheyden H, Jepsen S. Effects of bone morphogenetic protein-7 stimulation on osteoblasts cultured on different biomaterials. J Cell Biochem. 2002; 86(1): 90-8.

12. Kanayama M, Hashimoto T, Shigenobu K, Yamane S, Bauer TW, Togawa D. A prospective randomized study of posterolateral lumbar fusion using osteogenic protein-1 (OP-1) versus local autograft with ceramic bone substitute: emphasis of surgical exploration and histologic assessment. Spine (Phila Pa 1976). 2006;31(10):1067-74

13. Miller AF, Harvey SA, Thies RS, Olson MS. Bone morphogenetic protein-9. An autocrine/paracrine cytokine in the liver. J Biol Chem. 2000;275(24):17937-45.

14. Chen C, Grzegorzewski KJ, Barash S, Zhao Q, Schneider H, Wang Q, Singh M, Pukac L, Bell AC, Duan R, Coleman T, Duttaroy A, Cheng S, Hirsch J, Zhang L, Lazard Y, Fischer C, Barber MC, Ma ZD, Zhang YQ, Reavey P, Zhong L, Teng B, Sanyal I, Ruben SM, Blondel O, Birse CE. An integrated functional genomics screening program reveals a role for BMP-9 in glucose homeostasis. Nat Biotechnol. 2003;21(3):294-301.

15. Truksa J, Peng H, Lee P, Beutler E. Bone morphogenetic proteins 2, 4, and 9 stimulate murine hepcidin 1 expression independently of $\mathrm{Hfe}$, transferrin receptor 2 (Tfr2), and IL-6. Proc Natl Acad Sci U S A. 2006;103(27):10289-93.

16. López-Coviella I, Berse B, Krauss R, Thies RS, Blusztajn JK. Induction and maintenance of the neuronal cholinergic phenotype in the central nervous system by BMP-9. Science. 2000; 289(5477):313-6

17. Luo J, Deng ZL, Luo X, Tang N, Song WX, Chen J, Sharff KA, Luu HH, Haydon RC, Kinzler KW, Vogelstein B, He TC. A protocol for rapid generation of recombinant adenoviruses using the AdEasy system. Nat Protoc. 2007;2(5):1236-47

18. He TC, Zhou S, da Costa LT, Yu J, Kinzler KW, Vogelstein B. A simplified system for generating recombinant adenoviruses. Proc Natl Acad Sci US A. 1998; 95(5):2509-14..

19. Perrini S, Natalicchio A, Laviola L, Cignarelli A, Melchiorre M, De Stefano F, Caccioppoli C, Leonardini A, Martemucci S, Belsanti G, Miccoli S, Ciampolillo A, Corrado A, Cantatore FP, Giorgino R, Giorgino F. Abnormalities of insulin-like growth factor-I signaling and impaired cell proliferation in osteoblasts from subjects with osteoporosis. Endocrinology. 2008;149(3):1302-13.

20. The ministry of Science and Technology of the People's Republic of China. Guidance for experimental animal care; 2006-09-30. PRC. 2006

21. Zhao M, Xiao G, Berry JE, Franceschi RT, Reddi A, Somerman MJ. Bone morphogenetic protein 2 induces dental follicle cells to differentiate toward a cementoblast/osteoblast phenotype. J Bone Miner Res. 2002;17(8):1441-51

22. Ma Z, Li S, Song Y, Tang L, Ma D, Liu B, Jin Y. The biological effect of dentin noncollagenous proteins (DNCPs) on the human periodontal ligament stem cells (HPDLSCs) in vitro and in vivo. Tissue Eng Part A. 2008;14(12):2059-68.

23. Wu J, Jin F, Tang L, Yu J, Xu L, Yang Z, Wu G, Duan Y, Jin Y. Dentin non-collagenous proteins (dNCPs) can stimulate dental follicle cells to differentiate into cementoblast lineages. Biol Cell. 2008;100(5):291-302.

24. Sampath TK, Maliakal JC, Hauschka PV, Jones WK, Sasak H, Tucker RF, White KH, Coughlin JE, Tucker MM, Pang RH, et al. Recombinant human osteogenic pretein-1 (hOP-1) Induces new bone formation In vivo with a specific activity comparable with natural bovine osteogenic protein and stimulates osteoblast proliferation and differentiation In vitro. J Biol Chem. 1992;267(28):20352-62.

25. Ripamonti U, Reddi AH. Tissue engineering, morphogenesis, and regeneration of the periodontal tissues by bone morphogenetic proteins. Crit Rev Oral Biol Med. 1997;8(2):154-63.

26. Giannobile WV, Ryan S, Shih MS, Su DL, Kaplan PL, Chan TC. Recombinant human osteogenic protein-1 (OP-1) stimulates periodontal wound healing in class III furcation defects. J Periodontol. 1998;69(2):129-37.

27. Cochran DL, Wozney JM. Biological mediators for periodontal regeneration. Periodontol. 1999;19:40-58.

28. Hakki SS, Foster BL, Nagatomo KJ, Bozkurt SB, Hakki EE, Somerman MJ, Nohutcu RM. Bone morphogenetic protein-7 enhances cementoblast function in vitro. Periodontol. J Periodontol. 2010;81(11):1663-74.

29. Jin ZL, Zhang YK, Sun HY, Lin Z, Bi YC, Duan YZ, Ding Y. Osteogenic-related gene expression profiles of human dental follicle cells induced by dexamethasone. Acta Pharmacol Sin. 2008;29(9):1013-20.

30. Dangaria SJ, Ito Y, Walker C, Druzinsky R, Luan X, Diekwisch TG. Extracellular Matrix-Mediated Differentiation of Periodontal Progenitor Cells. Differentiation. 2009; 78(2-3):79-90.

31. Kémoun P, Laurencin-Dalicieux S, Rue J, Vaysse F, Roméas A, Arzate H, Conte-Auriol F, Farges JC, Salles JP, Brunel G. Localization of STRO-1, BMP-2/-3/-7, BMP receptors and phosphorylated Smad-1 during the formation of mouse periodontium. Tissue Cell. 2007; 39(4):257-66.

32. Huang GT, Gronthos S, Shi S. Mesenchymal Stem Cells Derived from Dental Tissues vs. Those from Other Sources: Their Biology and Role in Regenerative Medicine. J Dent Res. 2009; 88(9):792-806.

33. Huang $X$, Bringas P Jr, Slavkin HC, Chai Y. Fate of HERS during Tooth Root Development. Dev Biol. 2009;334(1):22-30.

34. Kang Q, Sun MH, Cheng H, Peng Y, Montag AG, Deyrup AT, Jiang W, Luu HH, Luo J, Szatkowski JP, Vanichakarn P, Park JY, Li Y, Haydon RC, He TC. Characterization of the disyinct orthotopic bone-forming activity of 14 BMPs using recombinant adenovirus-mediated gene delivery. Gene Ther. 2004;11(17):1312-20..

35. Chang H, Brown CW., Matzuk MM. Genetic analysis of the mammalian transforming growth factor-beta superfamily. Endocr Rev. 2002; 23(6):787-823

36. Lopez-Coviella I, Mellott TM, Kovacheva VP, Berse B, Slack BE, Zemelko V, Schnitzler A, Blusztajn JK. Developmental pattern of expression of BMP receptors and Smads and activation of Smad1 and Smad5 by BMP9 in mouse basal forebrain. Brain Res. 2006;1088(1):49-56.

37. Sharff KA, Song WX, Luo X, Tang N, Luo J, Chen J, Bi Y, He BC, Huang J, Li X, Jiang W, Zhu GH, Su Y, He Y, Shen J, Wang Y, Chen L, Zuo GW, Liu B, Pan X, Reid RR, Luu HH, Haydon RC, He TC. Hey1 basic helix-loop-helix protein plays an important role in mediating BMP9-induced osteogenic differentiation of mesenchymal progenitor cells. J Biol Chem. 2009; 284(1): 649-59.

38. Herrera B, van Dinther M, Ten Dijke P, Inman GJ. Autocrine bone morphogenetic protein-9 signals through activin receptor-like kinase-2/Smad1/Smad4 to promote ovarian cancer cell proliferation. Cancer Res. 2009;69(24):9254-62. 